\title{
The Atmospheric Response to Three Decades of Observed Arctic Sea Ice Loss
}

\author{
JAMES A. SCREEN AND IAN SIMMONDS \\ School of Earth Sciences, University of Melbourne, Melbourne, Victoria, Australia \\ Clara Deser AND Robert TOMAS \\ Climate and Global Dynamics, National Center for Atmospheric Research, * Boulder, Colorado
}

(Manuscript received 25 January 2012, in final form 12 June 2012)

\begin{abstract}
Arctic sea ice is declining at an increasing rate with potentially important repercussions. To understand better the atmospheric changes that may have occurred in response to Arctic sea ice loss, this study presents results from atmospheric general circulation model (AGCM) experiments in which the only time-varying forcings prescribed were observed variations in Arctic sea ice and accompanying changes in Arctic sea surface temperatures from 1979 to 2009. Two independent AGCMs are utilized in order to assess the robustness of the response across different models. The results suggest that the atmospheric impacts of Arctic sea ice loss have been manifested most strongly within the maritime and coastal Arctic and in the lowermost atmosphere. Sea ice loss has driven increased energy transfer from the ocean to the atmosphere, enhanced warming and moistening of the lower troposphere, decreased the strength of the surface temperature inversion, and increased lowertropospheric thickness; all of these changes are most pronounced in autumn and early winter (September-December). The early winter (November-December) atmospheric circulation response resembles the negative phase of the North Atlantic Oscillation (NAO); however, the NAO-type response is quite weak and is often masked by intrinsic (unforced) atmospheric variability. Some evidence of a late winter (March-April) polar stratospheric cooling response to sea ice loss is also found, which may have important implications for polar stratospheric ozone concentrations. The attribution and quantification of other aspects of the possible atmospheric response are hindered by model sensitivities and large intrinsic variability. The potential remote responses to Arctic sea ice change are currently hard to confirm and remain uncertain.
\end{abstract}

\section{Introduction}

The Arctic climate is changing rapidly, with potentially far-reaching repercussions (Symon et al. 2005; Solomon et al. 2007). Arctic sea ice is melting at an increasing rate (Serreze et al. 2007; Stroeve et al. 2007; Comiso et al. 2008; Stroeve et al. 2011; Comiso 2012). In September 2007, the Arctic sea ice reached its lowest areal extent in the satellite record, around $40 \%$ below the long-term mean (Comiso et al. 2008). The last five years (2007-11) have witnessed the five lowest September sea

\footnotetext{
* The National Center for Atmospheric Research is sponsored by the National Science Foundation.
}

Corresponding author address: James Screen, School of Earth Sciences, McCoy Building, University of Melbourne, Melbourne, 3010 Victoria, Australia.

E-mail: screenj@unimelb.edu.au ice extents in the modern record. In fact, the ice-covered area in recent summers is probably lower than at any other time in the past few thousand years (Polyak et al. 2010). The sea ice is also thinning rapidly (Kwok and Rothrock 2009; Maslanik et al. 2011; Kurtz et al. 2011) and therefore decreasing in volume (Schweiger et al. 2011). Observational evidence, coupled with climate models that unequivocally project continued loss of ice over the coming decades, points to an Arctic sea ice system in transition. Almost ice-free summers appear likely by the middle to end of this century (Stroeve et al. 2007; Boé et al. 2009), if not sooner (Wang and Overland 2009). Sea ice is a fundamental component of the earth's climate system and changes in its abundance have important implications for global weather and climate, as well as for polar ecosystems, indigenous communities, marine transportation, and resource management.

There is an increasing body of observational evidence that suggests ongoing reductions of Arctic sea ice may 
be impacting various aspects of weather and climate, both locally in the Arctic and remotely in the Northern Hemisphere midlatitudes. The dwindling Arctic ice cover has been cited as a cause of recent changes in Arctic air temperature and humidity (Serreze et al. 2009; Screen and Simmonds, 2010a,b; Kurtz et al. 2011), storm activity (Simmonds and Keay, 2009), and tropospheric circulation patterns (Francis et al. 2009; Overland and Wang 2010; Strong et al. 2010; Wu and Zhang 2010; Francis and Vavrus 2012; Jaiser et al. 2012), as well as trends in Siberian snow cover (Ghatak et al. 2010) and the occurrence of Eurasian cold winters (Honda et al. 2009; Petoukhov and Semenov 2010; Liu et al. 2012). Many of these linkages have been hypothesized based on statistical associations found in observations or atmospheric reanalyses, these being supported by plausible physical mechanisms. However, it is difficult to unambiguously assign causality and to separate the influences of multiple interconnected processes in the climate system using observations or reanalyses alone. Formal attribution and quantification of these changes to Arctic sea ice loss requires a different approach.

Modeling studies offer a way forward for understanding and isolating the physical processes underlying the relationships found in observational studies. In a model, the sea ice cover can be manipulated in a controlled manner to reveal how, and by what processes, it affects the wider climate system. A number of studies have imposed projected future sea ice conditions in atmospheric general circulation models (AGCMs) and examined the resulting atmospheric response [e.g., Singarayer et al. (2006); Seierstad and Bader (2009); Deser et al. (2010); see review papers by Budikova (2009) and Bader et al. (2011)]. For example, Deser et al. (2010) showed that projected Arctic sea ice loss accounts for most of the seasonal, spatial, and vertical structure of the high-latitude warming response to greenhouse gas forcing at the end of the twenty-first century. Other studies have imposed sea ice anomalies based on observations; however, these have applied forcings either in selected regions (Deser et al. 2004; Magnusdottir et al. 2004) or in selected seasons (Alexander et al. 2004; Bhatt et al. 2008). Furthermore, all of these studies using forcings based on observed sea ice anomalies were conducted prior to dramatic losses of Arctic sea ice in the past halfdecade. More recently, several studies have run AGCMs with prescribed observed sea ice concentrations to examine the atmospheric response to the record low sea ice extent in 2007 (Strey et al. 2010; Kumar et al. 2010; Orsolini et al. 2012; Blüthgen et al. 2012; Porter et al. 2012). While the aforementioned studies have provided significant insight into the aspects of the climate system that are most sensitive to sea ice loss, they cannot directly answer the question: what have been the likely atmospheric impacts of Arctic sea ice loss observed over the past three decades?

Our aim is to understand better the atmospheric changes that may have occurred in response to observed Arctic sea ice loss since 1979. To do so, we present results from a series of 31-yr model hindcasts in which the only time-varying forcings prescribed are variations in Arctic sea ice concentrations and directly associated Arctic sea surface temperature (SST) changes based on satellite observations between 1979 and 2009. The premise of these experiments is to isolate the atmospheric response to solely sea ice changes and, importantly, to quantify the response to realistic (rather than idealized), past (rather than projected future), and panArctic (rather than regional) sea ice changes. Our experiments differ from past studies in three key ways: 1 ) we use forcings that represent the sea ice changes observed over the past three decades, rather than projected changes or those observed in one highly anomalous year; 2) we implement a method for incorporating local SST adjustments related directly to sea ice changes; and 3) we adopt a multimodel approach in order to assess the robustness of the response between two independent climate models.

\section{Models and simulations}

Previous studies examining the atmospheric response to sea ice loss have used a single AGCM [with the notable exception of Kumar et al. (2010), who used three models; however, they only presented the multimodel mean thermal response, preventing any cross-model comparisons]. The responses identified differ among studies, which may arise in part because of sensitivity of the response to the particular model used. AGCMs are diverse with respect to factors such as model physics, horizontal and vertical resolution, subgrid-scale parameterizations, and in their representations of the mean climate and natural variability. These model differences, coupled with the different surface boundary forcings prescribed, complicate comparisons between past studies. With this in mind, we have conducted our experiments with identical forcings in two state-of-theart AGCMs to assess the robustness of the response between independently developed models.

We employ the National Center for Atmospheric Research (NCAR) Community Atmosphere Model version 3 (CAM3) and the UK-Australian Unified Model version 7.3 (UM7.3). CAM3 is the atmospheric component of the NCAR Community Climate System Model version 3 (CCSM3), which participated in phase 3 of the Coupled Model Intercomparison Project (CMIP3). It has 26 vertical levels and the experiments presented here use 
a spectral resolution of T42, roughly equivalent to $2.8^{\circ}$ of latitude and longitude. Full details on the physical and numerical methods used in CAM3 can be found in Collins et al. (2006) and references therein; details of the extensive model evaluation appear in a special issue of the Journal of Climate (Vol. 19, number 11, 2006). UM7.3 has been developed by the U. K. Met Office Hadley Centre and is the atmospheric model used in their Global Environmental Model version 2 (HadGEM2). UM7.3 is also the atmospheric model in the Australian Community Climate and Earth System Simulator (ACCESS). Both HadGEM2 and ACCESS are participating models in phase 5 of CMIP. The UM7.3 simulations presented here use 38 vertical levels extending to approximately $40-\mathrm{km}$ height and a horizontal resolution of $1.25^{\circ}$ latitude by $1.875^{\circ}$ longitude (often referred to as N96). Further details can be found in Martin et al. (2011) and references therein. Both atmospheric models were coupled to a distinct land surface model and the land surface boundary conditions were free to evolve. The oceanic surface boundary conditions (sea ice concentrations and SSTs) were prescribed. Greenhouse gases and other radiatively active chemical species were held constant.

A key consideration in this type of perturbed sea ice AGCM experiment is the prescription of SSTs and, possibly, SST changes. In the past the approach has been to either hold SSTs constant over all open water areas or to allow the SSTs over the whole domain to vary coherently with the sea ice. The advantage of the former approach is that it allows the impacts of sea ice change to be completely isolated. The disadvantages are that it may result in unrealistic temperature gradients in the surface boundary conditions and that SST changes due directly to sea ice changes are omitted. For instance, if an area becomes ice-free in summer, the SST will likely increase due to exposure to sunlight and the warmer atmosphere above. In summer 2007, it is estimated that the surface Arctic Ocean warmed by as much as $5^{\circ} \mathrm{C}$ in areas that became ice free (Perovich et al. 2008). This SST change could not have occurred if the sea ice cover had remained intact over these regions. Viewed in this light, this SST increase was an inherent and inseparable part of the sea ice loss. While the latter approach of allowing SSTs to vary coherently with the sea ice eliminates potentially unrealistic temperature gradients and incorporates the direct SST changes due to sea ice loss, it additionally includes SST changes not directly related to sea ice change. An example of the indirect effect is if sea ice changes induce atmospheric circulation anomalies and therefore drive nonlocal SST changes. More importantly, if the SSTs are allowed to vary coherently, they will also include SST changes that are completely independent of sea ice change. Thus, the identified atmospheric response cannot be attributed to solely sea ice change, but it is a combined response to sea ice and SST change. The responses identified by Orsolini et al. (2012), Blüthgen et al. (2012), and Porter et al. (2012) fall into this category.

Here we propose and implement an alternative approach. In locations where the sea ice cover did not change we held SSTs constant. However, in regions where the sea ice cover changed we allowed the SSTs to change also. Specifically, the following procedure was applied to create the surface boundary conditions for our experiments. The source data for our boundary conditions are the Hurrell et al. (2008) monthly-mean observed SSTs and sea ice concentrations updated through 2009. In the marginal ice zone, each grid box contains a value for both sea ice concentration and the SST of open water. These data were regridded to the respective model grids prior to deriving the boundary conditions [after Hurrell et al. (2008)]. Then, at each grid box and for each month, we calculated the climatological mean SST and sea ice concentration over the period 1950-2000. For grid boxes north of $40^{\circ} \mathrm{N}$, if the sea ice concentration observed during a particular month deviated from the climatological mean by more than $10 \%$ (in absolute terms), the observed sea ice concentration and SST values were used. South of $40^{\circ} \mathrm{N}$ and at grid boxes where the monthly mean sea ice concentration was within $10 \%$ of the climatological mean, the climatological sea ice concentration and/or SST values were used. This procedure captures observed changes in Arctic sea ice and changes in Arctic SST that are directly associated with the ice changes, but does not capture SST changes that are not directly related to sea ice variations. It enables the response to sea ice changes to be isolated, but without discounting the direct SST changes due to sea ice variations, which we consider to be an implicit part of the response to sea ice changes. Prescribing sea ice concentrations (rather than sea ice extent) means that changes in lead fraction are accounted for in our simulations. Changes in snow-on-ice and melt-pond fraction are not prescribed, but are simulated or parameterized within the models. Observations suggest that the Arctic sea ice cover has thinned over recent decades (Kwok and Rothrock 2009; Maslanik et al. 2011). Unfortunately, no suitable dataset of observed sea ice thicknesses exist that could be used in our experiments (observations are limited in space and time). Therefore, the sea ice thickness was fixed at $2 \mathrm{~m}$ throughout the Arctic in the CAM3 experiments. In the UM7.3 experiments, fully ice-covered grid boxes were given a thickness of $2 \mathrm{~m}$ whereas in partially icecovered grid boxes the sea ice thickness was calculated by the model as a function of the sea ice concentration 




FIG. 1. Linear changes from 1979 to 2009 in (top) sea ice concentrations and (bottom) sea surface temperatures. SST changes are confined to areas of sea ice change by design (see text).

(the Arctic-mean climatological sea ice thickness ranged from $1.87 \mathrm{~m}$ in March to $1.65 \mathrm{~m}$ in August). We speculate that our simulations may underestimate the real response to Arctic sea ice loss as they do not explicitly include the observed thinning of the sea ice cover.

Figure 1 shows the 31-yr linear changes in our surface boundary conditions. Note that the prescribed forcings include the full observed month-to-month variability as well as the long-term trends shown here. The main effect of allowing the SSTs to vary in the manner described is that the boundary conditions include warming SSTs in the regions of ice loss. This warming signature is most pronounced in summer and autumn over the Beaufort, Chukchi, and East Siberian (B-C-ES) Seas, but SST changes (directly related to sea ice trends) are apparent in all seasons. Previous studies that have used constant SSTs (e.g., Strey et al. 2010; Kumar et al. 2010) do not include this direct SST warming effect due to increased open water and, thus, are missing a potentially important forcing component of Arctic sea ice loss. In the marginal ice zone the models calculate the surface fluxes separately over the ice-covered and open water fractions of the grid box, so changes in both the sea ice concentration and the SST of open water will impact the surface energy budget of that grid box.

Our approach of prescribing the full month-to-month evolution of Arctic sea ice concentrations differs from past studies that have performed two sets of simulations, one with "low" sea ice extents (often from 2007, the lowest September sea ice cover on record) and the other with "high" or "normal" sea ice extents, with the difference between the two sets being used as an indication of the atmospheric response to sea ice change (e.g., Strey et al. 2010; Kumar et al. 2010; Orsolini et al. 2012; Blüthgen et al. 2012; Porter et al. 2012). These previous sea ice forcings are not fully representative of the observed multidecadal changes; in general, past forcings are overly strong and too far poleward compared to the observed long-term trend (not shown). Both magnitude and location of the forcing may be critically important to the atmospheric response. This complicates the interpretation of past results (focused on 2007) in the context of longer term trends. We argue that our forcing fields, which are based on long-term observations rather than individual (anomalous) years, provide a truer test of the atmospheric response to the past three decades of observed Arctic sea ice loss.

All of our simulations cover the 31-yr period from 1979 to 2009. To account for the effects of atmospheric intrinsic variability on our results, we have conducted ensembles of simulations with both models. Each ensemble member started from different atmospheric initial conditions but they are identical in every other respect. We have performed five ensemble members using CAM3 and eight ensemble members using UM7.3. We predominantly analyze the ensemble means from each model. The ensemble-mean linear changes between 1979 and 2009 were computed using least squares linear regression. Throughout the manuscript we present the linear changes over the full 31 years rather than the changes per year, or per decade. These ensemblemean linear changes are referred to as the atmospheric 
response to Arctic sea ice loss. The response is considered to be robust within a particular model when the ensemble-mean linear regression is statistically significant at the $95 \%$ level based on a two-sided Student's $t$ test. On occasion, we present the responses in the individual ensemble members to enable a qualitative assessment of the robustness of the responses. Comparison of the ensemble-mean responses between the two models allows for an assessment of the robustness of the responses between models.

\section{Results}

The remainder of the manuscript is organized as follows. We start by examining the surface heat budget responses in section $3 \mathrm{a}$. Informed by the heat flux responses, section $3 \mathrm{~b}$ examines the atmospheric temperature responses and also the associated changes in lower atmospheric stability. Section $3 \mathrm{c}$ considers the humidity, cloud cover, and precipitation responses. The tropospheric circulation responses are detailed in section $3 \mathrm{~d}$, and finally in section $3 \mathrm{e}$ we briefly consider the impacts of sea ice loss on the stratosphere. We primarily present two-month-mean responses for January-February (midwinter), March-April (late winter), May-June (spring), July-August (summer), September-October (autumn), and November-December (early winter). From here on, the "seasons" correspond to the twomonth seasons just defined, unless explicitly stated otherwise.

\section{a. Surface energy budget response}

One of the principal ways that Arctic sea ice loss can affect the overlying atmosphere is through modifying the surface heat budget. Figure 2 shows maps of the surface turbulent heat flux responses (sensible plus latent heat fluxes) and the net (outgoing minus incoming) surface longwave radiative flux responses. Figure 3 summarizes the responses of the individual heat budget terms and the net ocean-to-atmosphere heat budget averaged over the Arctic Ocean as a whole. In both figures all fluxes are defined as positive in the upward direction such that a positive heat flux response has a warming influence on the overlying atmosphere.

The largest turbulent heat flux responses occur in the autumn and early winter and are collocated with the regions of greatest sea ice loss (cf. Figs. 1 and 2). The sensible and latent heat flux responses closely resemble each other (not shown). Significant positive responses are found in both models over the B-C-ES Seas in autumn; over the Chukchi Sea, Barents Sea, and Hudson Bay in early winter; and over the Barents Sea and Sea of Okhotsk in middle and late winter. The turbulent heat flux responses are weak in spring and summer. Averaged over the Arctic Ocean, the sensible heat flux responses peak in November, one month later than the maximum latent heat flux responses (Fig. 3). However, the latent and sensible heat flux responses peak at comparable valuesmore than $25 \mathrm{~W} \mathrm{~m}^{-2}$ locally or around $2.5 \mathrm{~W} \mathrm{~m}^{-2}$ averaged over the entire Arctic Ocean. The largest responses occur during autumn and early winter when the ocean rapidly loses heat to the atmosphere because of the large air-sea temperature difference and rapid ice growth at this time of year. This seasonality in the surface heat flux response to changes in sea ice is well known and has been identified in models and reanalyses (e.g., Deser et al. 2010; Screen and Simmonds 2010b).

The turbulent heat fluxes display negative responses in regions adjacent to sea ice loss (and therefore adjacent to the positive flux responses); for example, over the Bering Sea in early winter and off the Pacific coast of the Kamchatka Peninsula in late winter. These dipoles can be understood by considering that the lower atmospheric warming above the regions of sea ice loss spreads to adjacent regions, as we will show later. If there is no sea ice present, this warmer air loses some of its excess heat to the ocean. Note that in our experiments the SSTs are held constant outside of the regions of sea ice loss. In reality, the ocean would warm in the regions with negative flux responses (recall that a negative response implies an increase in heat transfer from the atmosphere to the ocean), which would act to dampen the negative flux response by reducing the air-sea temperature difference. Thus, such dipole features are likely to be overly pronounced in our simulations owing to the lack of a coupled ocean component. However, similar dipole features are still found in fully coupled model simulations (Deser et al. 2010) and can also be seen in recent trends derived from atmospheric reanalyses (Screen and Simmonds 2010b). Both models suggest an increase in oceanic heat loss over the North Atlantic in the autumn and early winter. These increases lie farther south than the prescribed SST and sea ice changes (Fig. 1) and imply a remote response to sea ice loss. They are likely associated with circulation changes that will be discussed later (section 3d). In mid and late winter the heat flux responses over the North Atlantic differ between the models, which likely reflects differences in the circulation responses over this region.

The most robust feature of the longwave responses between the two models is the positive responses over the B-C-ES Seas in autumn (Fig. 2). This reflects greater longwave emissions from the warmer ocean surface (Fig. 1). This feature is, however, larger in magnitude in CAM3 than UM7.3 (Fig. 2)-a difference that is also reflected in the Arctic Ocean averages, with CAM3 


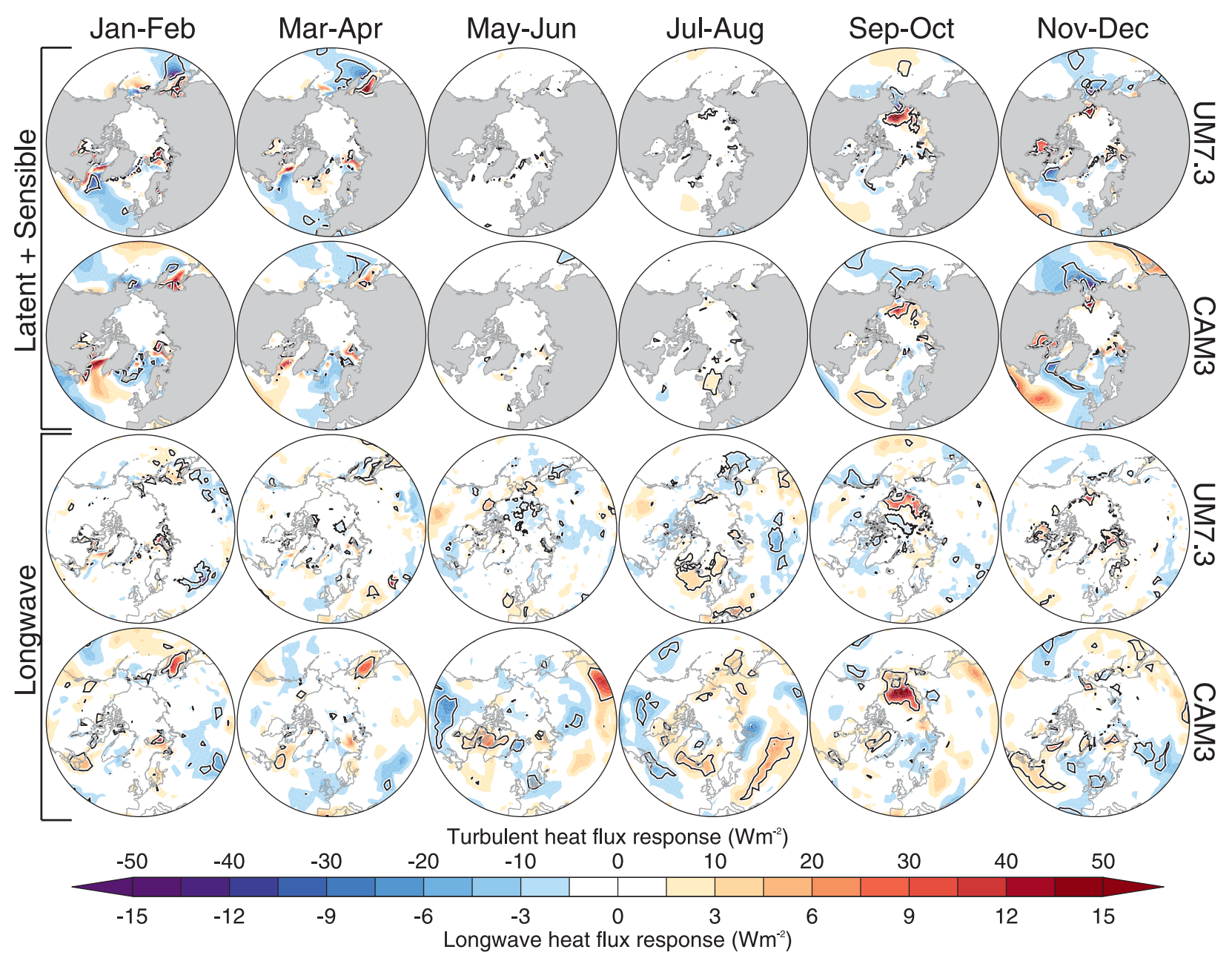

FIG. 2. (top two rows) Ensemble-mean turbulent (sensible and latent) heat flux responses and (bottom two rows) net surface longwave radiation responses in the two models. Fluxes are defined positive in the upward direction. Black lines denote ensemble-mean linear responses that are statistically significant at the $95 \%$ level.

showing a much larger longwave response in September than UM7.3 (Fig. 3). In UM7.3 the increase in outgoing longwave radiation due to a warmer ocean surface is largely offset by collocated increases in incoming longwave radiation due to more low-level cloud cover (see section 3c). The same reasoning explains why CAM3 has larger longwave increases over the Sea of Okhotsk in mid and late winter. Other differences between the longwave responses in the two models also reflect differences in the humidity and cloud cover responses that will be discussed later. For example, CAM3 shows statistically significant responses of opposite sign over central North America and China during spring and an expansive positive response over central Eurasia in summer, none of which is apparent in UM7.3.

The net solar (shortwave) responses are similar in the two models and the largest responses are found over the
Sea of Okhotsk in late winter; the Barents Sea, Hudson Bay, and the Canadian Archipelago in spring; and over the B-C-ES Seas during summer and autumn (not shown). All of these regions display significant negative solar responses (i.e., less outgoing solar radiation) due primarily to sea ice loss and the resulting lower surface albedo. It should be noted that, because of the prescription of SSTs, energy absorbed by the model ocean is not permitted to warm it. However, our forcing incorporates local SST adjustments due to changing sea ice cover and, thus, the ice-albedo feedback is implicitly included in our simulations.

Summing the heat budget terms (sensible, latent, and longwave; for the reasoning above the solar term is not included in our definition of the net heat budget), it can be seen that the Arctic-mean influence of sea ice loss on ocean-to-atmosphere heat exchange is greatest in 

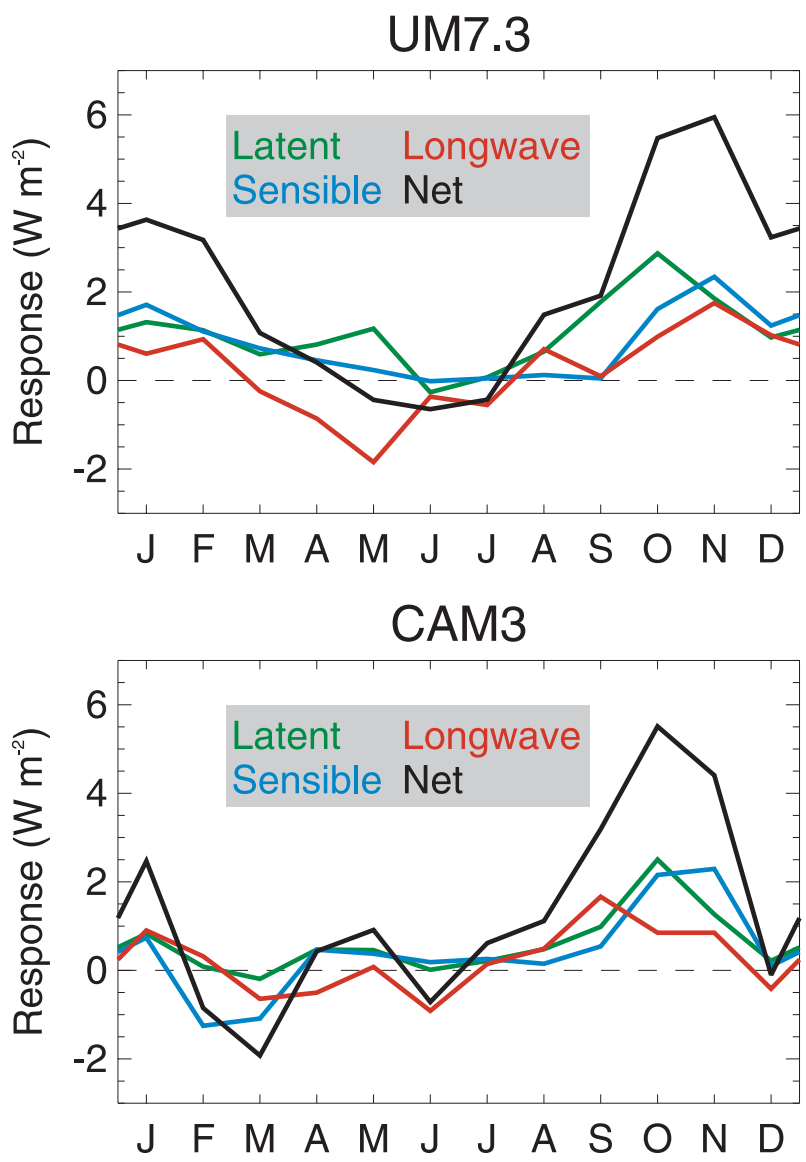

FIG. 3. Ensemble-mean responses of the surface energy budget terms in the two models averaged over the Arctic Ocean (all grid boxes north of $65^{\circ} \mathrm{N}$ with $<50 \%$ ocean cover). Fluxes are defined positive in the upward direction.

October-November (Fig. 3). This is in close agreement with previous studies (e.g., Deser et al. 2010; Porter et al. 2012). In the winter months (December-March), the net flux response is appreciably larger in UM7.3 than in CAM3, primarily due to larger turbulent heat flux increases in UM7.3. This difference between the model flux responses appears to be caused by differences in the climatological-mean winter near-surface temperatures. Figure 4 shows vertical profiles of climatologicalmean air temperatures averaged north of $65^{\circ} \mathrm{N}$. During the winter months, near-surface temperatures are colder in UM7.3 than in CAM3 (by as much as $5^{\circ} \mathrm{C}$ in the Arctic mean). These colder near-surface temperatures result in a stronger climatological-mean surface temperature inversion in UM7.3 than in CAM3 (defined here as the temperature difference between 850 and $1000 \mathrm{hPa}$ ). Accordingly, there is a larger air-sea temperature difference, which facilitates a greater turbulent heat flux response in UM7.3 than in CAM3 (under the same prescribed surface forcing). In both

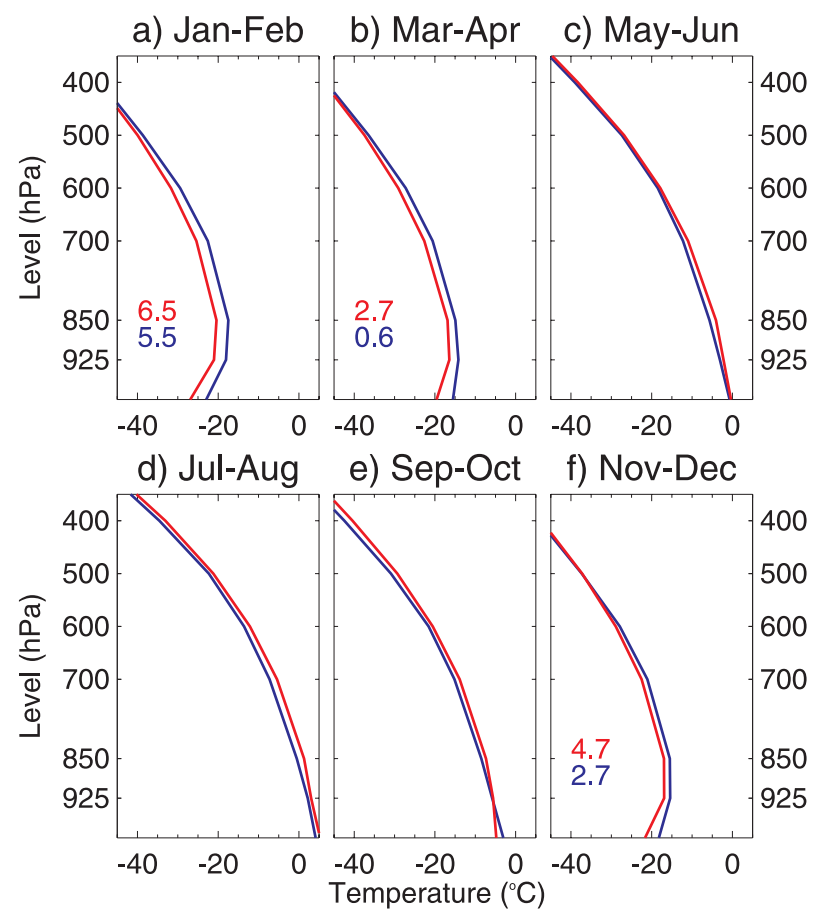

FIG. 4. Ensemble-mean climatological-mean temperature profiles in the two models (red for UM7.3, blue for CAM3) averaged over the Arctic (all grid boxes north of $65^{\circ} \mathrm{N}$ ). The colored numbers show the climatological-mean inversion strength, defined as the $850-\mathrm{hPa}$ temperature minus the $1000 \mathrm{-hPa}$ temperature (larger numbers denote a stronger inversion; negative values would imply an absence of a climatological surface inversion and are not shown).

models, the ocean-to-atmosphere heat budget responses are weak in April through to July (Fig. 3). We now consider how these changes in the surface heat budget affect the thermal structure of the atmosphere.

\section{b. Atmospheric temperature response}

Figure 5 (first and second rows) present maps of the 925-hPa (lower tropospheric) temperature response. UM7.3 and CAM3 show reasonably similar temperature responses during autumn through to spring. There is a very distinct seasonal and spatial structure to the response that reflects the changes in the surface heat budget identified above. Over the Arctic Ocean the warming response peaks in autumn and early winter. In autumn the warming is centered over the B-C-ES Seas. In early winter the warming response covers the western Arctic Basin from the Chukchi Sea to Baffin Bay. Large and significant warming responses are also apparent in mid and late winter over lower-latitude regions of ice loss, including over Hudson Bay, the Sea of Okhotsk, and the Barents Sea.

The models exhibit differences in their temperature responses despite the same prescribed boundary 


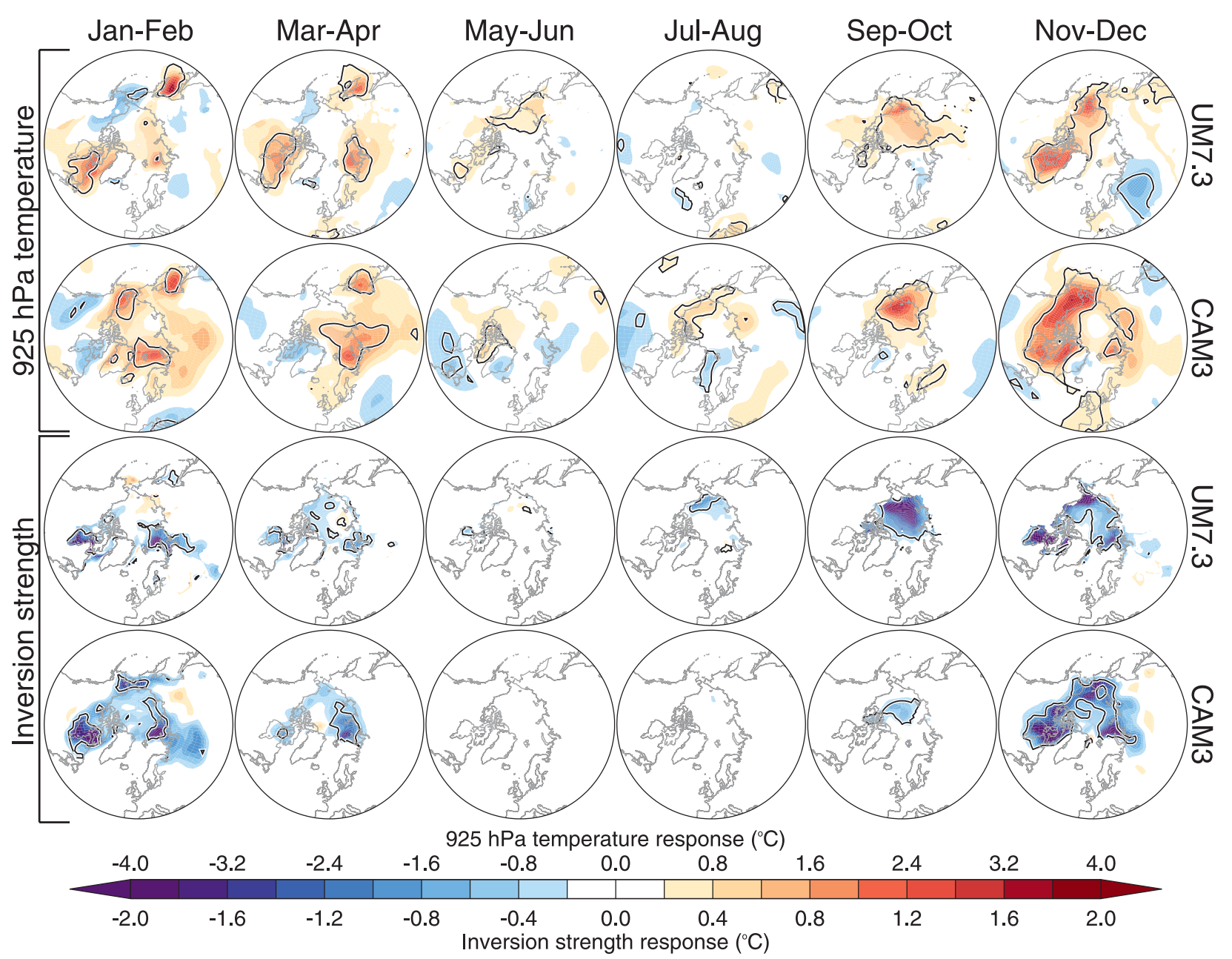

FIG. 5. Ensemble-mean (top two rows) 925-hPa air temperature responses and (bottom two rows) inversion strength ( $\left.T_{850-1000}\right)$ responses in the two models. Black lines denote ensemble-mean linear responses that are statistically significant at the $95 \%$ level.

conditions. For example, UM7.3 shows a significant cooling response over northeastern Europe during early winter that is not found in CAM3. Another difference between the models is the extent to which the warming response spreads over the Arctic landmasses. In general, the terrestrial warming responses cover a larger area in CAM3 than they do in UM7.3. A good example is the temperature response over sub-Arctic North America in early winter. CAM3 shows a broad-scale warming response from Alaska to Quebec. In contrast, the response in UM7.3 is more confined to the coastal regions surrounding Hudson Bay and the Beaufort Sea. Similarly, the early and midwinter terrestrial warming responses over northern Russia are larger in CAM3 than UM7.3. This appears to reflect, in part, a more widespread climatological surface temperature inversion in CAM3 compared to UM7.3. While UM7.3 depicts a stronger climatological-mean inversion than CAM3 (Fig. 4),
CAM3 depicts inversions over more extensive regions of the high-latitude landmasses than UM7.3 (not shown). Thermal inversions can amplify the warming response by restricting vertical mixing, so that the warming remains confined to the near-surface layers, and by reducing the efficiency of infrared radiative cooling (Bintanja et al. 2011).

Figure 6 (shading) shows the zonal-mean air temperature responses. For now we focus on the responses in the troposphere (below $350 \mathrm{hPa}$ ) as the stratospheric responses will be discussed in section $3 \mathrm{e}$. The characteristic signature of Arctic temperature amplificationwarming that is most pronounced in autumn and early winter and strongest in the lowermost atmosphere (Serreze et al. 2009; Screen and Simmonds 2010a; Serreze and Barry, 2011; Screen et al. 2012)—is clearly seen in both models. For comparison the net ocean-toatmosphere heat flux responses are also shown by the 

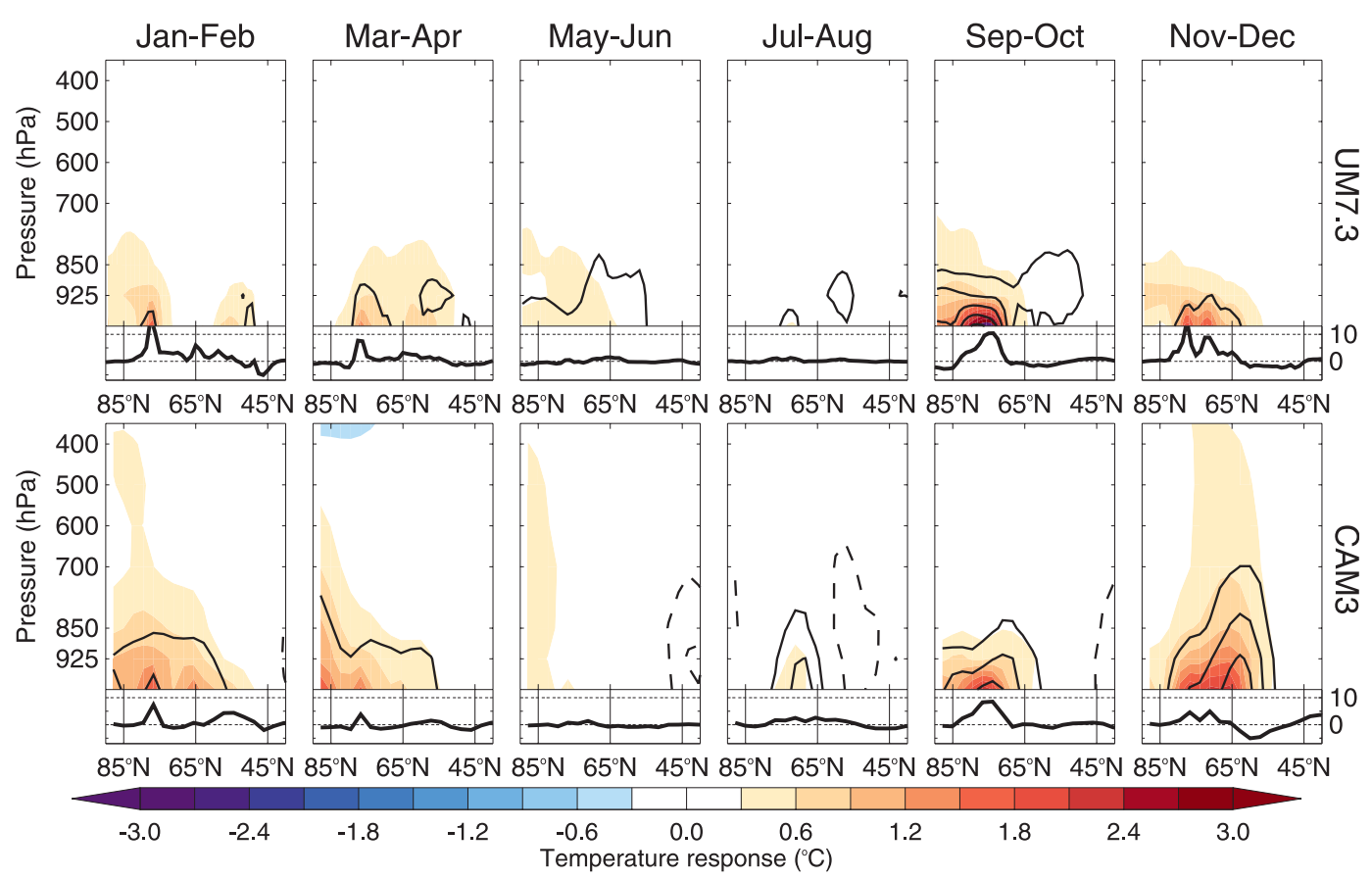

FIG. 6. Vertical profiles of the zonal- and ensemble-mean air temperature responses (shading) and specific humidity responses (contours) in the two models. Contours are drawn at intervals of $1 \mathrm{~g} \mathrm{~kg}^{-1}$ with solid contours denoting a positive response and dashed contours denoting a negative response. The zero contour is not plotted. The line graphs show the corresponding zonal- and ensemble-mean net ocean-to-atmosphere heat flux responses.

line plots in Fig. 6. The strong correspondence between the lower atmospheric warming and the surface heat flux responses within the Arctic (north of about $70^{\circ} \mathrm{N}$ ) is striking. Thus, the dominant mechanism by which Arctic sea ice loss has affected lower tropospheric air temperature is through enhanced ocean-to-atmosphere heat fluxes in fall and winter, consistent with results from reanalyses (Screen and Simmonds 2010b).

Interestingly, the warming responses are almost entirely confined to the lowermost troposphere (below $850 \mathrm{hPa}$ ) in both models. The strong surface intensification of the warming response is one of the most robust features of the simulated atmospheric response to Arctic sea ice loss (Deser et al. 2010; Strey et al. 2010; Kumar et al. 2010; Screen et al. 2012; Porter et al. 2012). We find little evidence of an ice-driven temperature response above $850 \mathrm{hPa}$. The one notable exception is in CAM3 during early winter when there is a deep warming response throughout the troposphere. This deep warming response, centered at $65^{\circ}-70^{\circ} \mathrm{N}$, lies to the south of the largest surface heat flux response and is collocated with regions of strong surface temperature inversions (not shown). This suggests that this elevated warming response is sustained not by surface heating but, more likely, by horizontal heat advection because of circulation changes (see section 3d). A number of previous studies have shown that changes in atmospheric heat transport induce Arctic warming aloft, with a maximum thermal response located in the midtroposphere (Graversen et al. 2008; Yang et al. 2010; Chung and Räisänen 2011; Porter et al. 2012). Screen et al. (2012) show that the observed Arctic warming aloft is likely remotely driven by SST changes outside the Arctic and consequent increases in poleward heat transport into the Arctic.

The strongly surface-based warming response has implications for the thermal structure of the lower troposphere. Figure 5 (third and fourth rows) show the changes in the strength of the surface temperature inversion, defined as the temperature difference between 850 and $1000 \mathrm{hPa}\left(T_{850-1000}\right)$ when $T_{850-1000}$ is greater than zero. In autumn through to late winter, the inversion weakens in response to sea ice loss in both models. This weakening of the inversion has been noted in autumn using reanalyses (Schweiger et al. 2008), suggesting that it is a realistic feature of the response to sea ice loss. The largest changes are in early and mid winter and in the immediate proximity of sea ice loss (and strong near-surface warming). The response spreads to nearby land regions in CAM3, but is mostly confined to oceanic regions in UM7.3. UM7.3 shows larger changes in inversion strength during autumn than 
does CAM3, despite comparable warming responses. This difference between the inversion strength responses, like that in the turbulent heat flux responses, reflects differences in the mean states of the two models. UM7.3 depicts surface inversions more often and more widely during autumn than does CAM3 (hence the stronger climatological-mean inversion in UM7.3; see Fig. 4). The same reasoning explains the differences in the responses in summer over the marginal Arctic Seas.

\section{c. Humidity, cloud, and precipitation responses}

Zonal-mean specific humidity responses are shown by the black contours in Fig. 6. Contrasting the humidity responses with the temperature responses (shading in Fig. 6), it can be seen that the tropospheric responses are intimately connected. All latitudes with significant lower atmospheric warming responses display a moistening response, as one might expect based on the ClausiusClapeyron equation. Some of this additional moisture has a local source, as many of the moistening responses overlie regions of enhanced evaporation due to sea ice loss (not shown). Again, the responses are mainly confined to the lower troposphere with the exception of a deeper moistening response in CAM3 in early winter and a mid to lower tropospheric drying response in CAM3 during summer. The differences in the humidity responses between the models can be reasonably well explained by the differences in the temperatures responses. For example, the deeper moistening response in CAM3 during early winter is linked to the deep warming response centered at $65^{\circ} \mathrm{N}$; the more extensive moistening response in CAM3 during midwinter is linked to its more extensive warming response; and the stronger moistening in UM7.3 during spring can be traced back to larger warming in this model during this season.

The low cloud cover responses (Fig. 7; first and second rows) are quite "noisy" and show no large-scale statistically significant features that are robust across the two models. The most notable aspect of the responses are increases in low cloud cover over regions of ice loss in UM7.3. These increases in low-level cloudiness are consistent across all regions of ice loss from autumn to late winter (September to April) in UM7.3, but are not seen in any season in CAM3. In UM7.3, the total cloud cover also increases in regions of sea ice loss (not shown). The warmer, more moist atmosphere appears conducive to a greater abundance of low cloud cover in UM7.3. Satellite measurements support low-level cloud increases in response to more open water in autumn (Kay and Gettelman 2009; Palm et al. 2010), although Schweiger et al. (2008) suggested that Arctic low cloud may decrease in autumn because of weaker surface inversions, rising cloud heights, and a consequent increase of medium-level cloud at the expense of low-level cloud. The response in UM7.3 is very robust and is clearly identifiable in all eight ensemble members (not shown). However, despite broadly comparable temperature and humidity responses, there are no such increases in low cloud in any of the CAM3 ensemble members. The differences cannot be reconciled by intrinsic variability (ensemble size) and, thus, demonstrate model sensitivities in the cloud cover response to sea ice loss. As mentioned earlier, these differences in the cloud cover responses between models impact their respective radiative flux responses. We next show that these differences also affect the precipitation responses.

Figure 7 (third and fourth rows) shows the total precipitation responses. As with the cloud cover responses, there are few large-scale significant features. However, the regions of increased low cloud cover in UM7.3 also show increased precipitation. These increases occur predominantly over ocean regions: the B-C-ES Seas in autumn, Chukchi Sea in early winter, and Barents Sea and Sea of Okhotsk in mid and late winter. In UM7.3, the latent heat flux, humidity, cloud cover, and precipitation responses are all closely linked and respond coherently in regions of sea ice loss. In CAM3, the latent heat flux and humidity responses are linked and respond coherently to sea ice loss, but they do not translate into cloud cover or precipitation changes. This may reflect deficiencies in the representation of Arctic low clouds in CAM3 (Vavrus and Waliser 2008). Using the Weather Research and Forecasting (WRF) model, Strey et al. (2010) identified October-November precipitation increases over the central Arctic in response to reduced sea ice. Using the same model but with slightly different physics options and surface boundary conditions, Porter et al. (2012) noted increased low cloud cover and precipitation over the B-C-ES Seas during October in response to sea ice loss. These responses in the WRF model are in qualitative agreement with the autumn response in UM7.3 over the Arctic Ocean and not with the lack of a response in CAM3.

One aspect of the precipitation responses that is reasonably robust between CAM3 and UM7.3 is the changes in precipitation form (i.e., the proportion of solid versus liquid precipitation). Both models display significant decreases in the snowfall fraction over the B-C-ES Seas in summer (not shown). Screen and Simmonds (2012) found a decrease in summer (June-August) snowfall fraction over the Arctic Ocean and northern Canada based on reanalyses and observations. That study showed very close links between the snowfall changes and lower atmospheric warming but did not directly examine the causes of the warming. The model evidence presented here suggests that at least part of the observed 


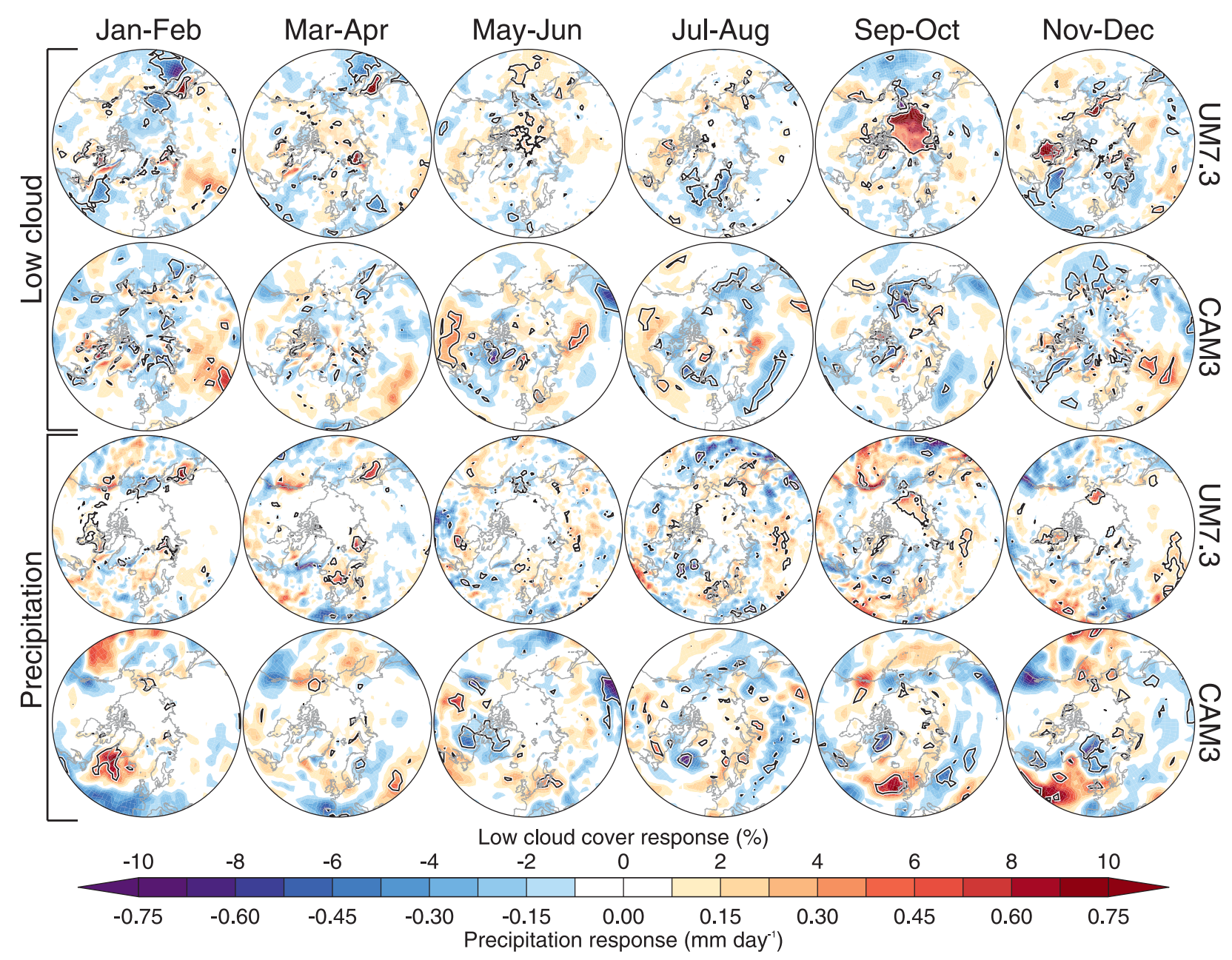

FIG. 7. Ensemble-mean (top two rows) low cloud cover responses and (bottom two rows) precipitation responses in the two models. Black lines denote ensemble-mean linear responses that are statistically significant at the $95 \%$ level.

summer snowfall decline is driven by Arctic sea ice loss.

\section{d. Atmospheric circulation response}

The ensemble-mean 700-1000-hPa thickness (the depth of the atmospheric layer between 700 and $1000 \mathrm{hPa}$ ) responses are shown in Fig. 8 (first and second rows). The thickness fields are insightful as they provide an integrated measure of changes in a deep layer of the atmosphere rather than focusing on any specific pressure level or altitude. Thickness fields have been successfully used in previous studies to characterize the lower-tropospheric circulation response to changes in sea ice (e.g., Overland and Wang 2010; Francis and Vavrus 2012). The thickness responses display significant increases over the Arctic Ocean in autumn, especially strong over the B-C-ES Seas, in both models. The regions of increased thicknesses correspond to regions of increased ocean-to-atmosphere heat fluxes and lower-tropospheric warming, which has the effect of raising the geopotential height surfaces. Increased thicknesses are also found over the Chukchi Sea in early winter in both models, over Alaska and northern Canada in early winter in CAM3 only, and over regions of ice loss in mid and late winter (Sea of Okhotsk, Hudson Bay, Barents Sea). Statistically significant decreases in thicknesses are found over northeast Europe in early winter in UM7.3 (but not CAM3). These thickness changes indicate a causal link between Arctic sea ice loss and lower-tropospheric circulation changes, supporting similar linkages shown empirically by Overland and Wang (2010).

Figure 8 (third and fourth rows) shows the ensemblemean $500 \mathrm{hPa}$ (midtropospheric) geopotential height $\left(Z_{500}\right)$ responses. We note that by averaging across ensemble members, changes in weather systems that are 


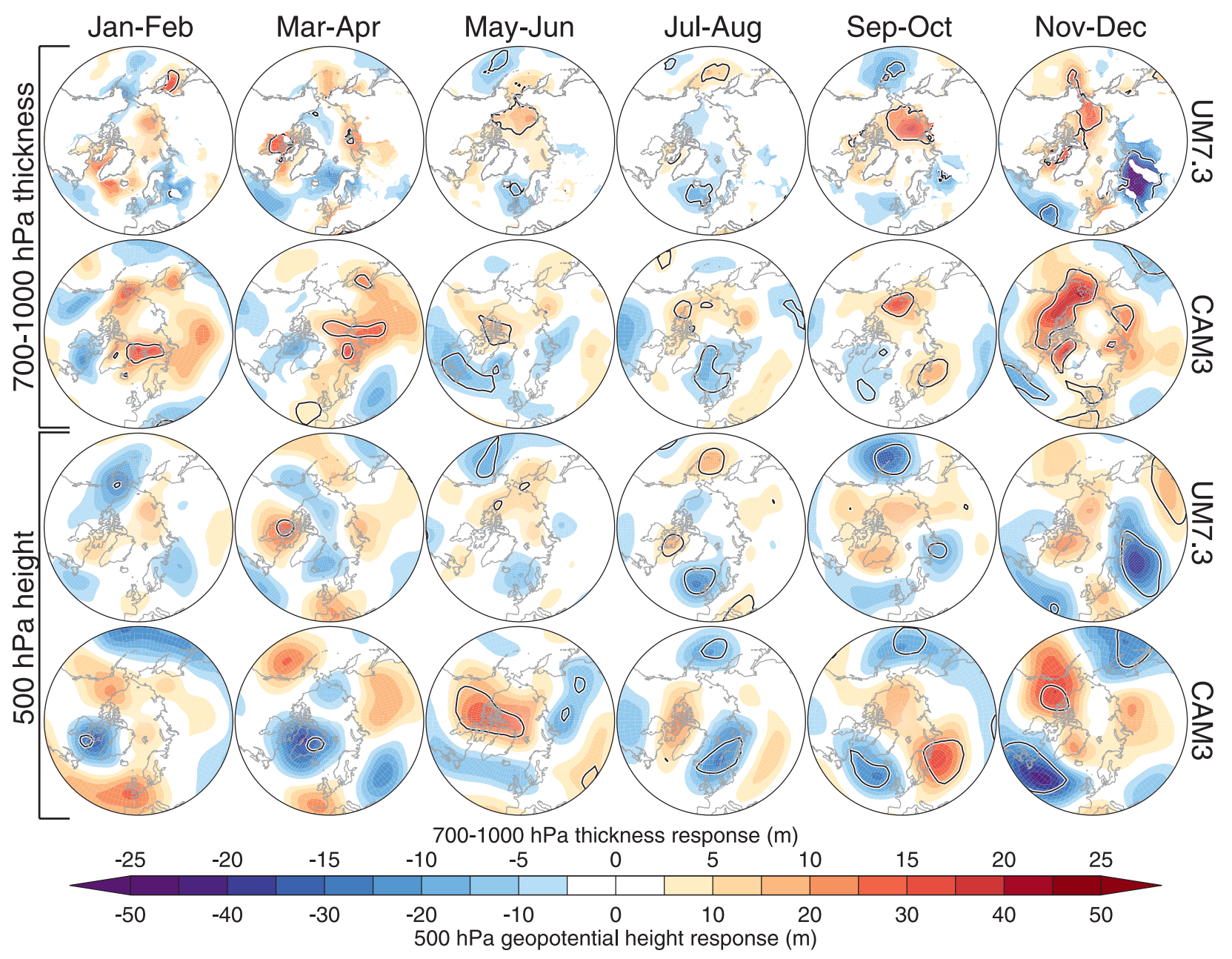

FIG. 8. Ensemble-mean mean (top two rows) 700-1000-hPa thickness responses and (bottom two rows) 500-hPa geopotential height responses in the two models. Black lines denote ensemble-mean linear responses that are statistically significant at the $95 \%$ level.

not consistently located in one region (e.g., blocking events, storms) may be obscured. However, our focus here is not on the synoptic-scale responses but rather on the larger spatial- and temporal-scale circulation responses, and averaging across members is necessary in an attempt to separate the forced response from intrinsic atmospheric variability. The $Z_{500}$ responses in any given season differ more between the two models than do the thickness responses. This likely reflects that the $Z_{500}$ is a more "noisy" field with larger intrinsic variability. There are few features of the $Z_{500}$ responses that are statistically significant in both models. Unlike the cloud and precipitation response differences earlier however, it is not possible to attribute these disparities in the $Z_{500}$ response to differing model physics. The reason for this is that the $Z_{500}$ responses are not robust across the ensemble members of either model. The ensemble-mean $Z_{500}$ responses mask a large degree of variability between ensemble members for any given season and in both models. These differences between ensemble members can only be caused by intrinsic atmospheric variability. It is therefore very likely that the apparent differences between the ensemble-mean $Z_{500}$ responses from the two models are also caused in large part by intrinsic variability masking any potential forced $Z_{500}$ responses. This small "signal-to-noise" ratio hampers the assessment of the $Z_{500}$ (and sea level pressure; not shown) response to Arctic sea ice loss; however, there are a few aspects of the response that appear relatively robust and worthy of further discussion.

Although far from identical, there is some commonality to the autumn and early winter circulation responses. Both models show $Z_{500}$ decreases over the North Pacific in autumn. In early winter both models depict $Z_{500}$ increases over the Arctic Ocean and/or Greenland and $Z_{500}$ decreases over the North Atlantic 
(Fig. 8, third and fourth rows). These features can also be seen in the 700-1000-hPa thickness responses (Fig. 8, first and second rows). These aspects of the responses show some resemblance to the negative phase of the North Atlantic Oscillation (NAO), which is characterized by high $Z_{500}$ anomalies over Greenland and low $Z_{500}$ anomalies across the Atlantic Ocean from New England to Portugal (Fig. 9, top row). Here we define the NAO index as the normalized $Z_{500}$ difference between $68^{\circ}$ and $40^{\circ} \mathrm{N}$ over the Atlantic sector $\left(0^{\circ}-80^{\circ} \mathrm{W}\right)$, which captures well the NAO signature in both models. Figure 9 (bottom) shows the NAO index responses, both for the ensemble means and each member. Both models show ensemble-mean shifts toward the negative phase of the NAO during early winter. Seven of the eight UM7.3 members show decreases in the NAO index, three of which show normalized decreases of less than -1 . Four of five CAM3 members also show NAO decreases, although only one member shows a normalized response close to -1 . Although none of the singlemember NAO responses is statistically significant at the $95 \%$ level (the stronger responses are significant at the $80 \%-90 \%$ level), there does appear to be broad agreement between the two models (and most of their ensemble members) in that they show a negative NAOtype response in early winter. In autumn and mid to late winter there is no such agreement; in fact, during autumn and midwinter the two models show opposite ensemble-mean responses (Fig. 9). The large imprint of intrinsic variability can be seen by the wide spread of responses in the ensemble members, especially in UM7.3 during midwinter.

Figure 10 shows the Atlantic sector $\left(0^{\circ}-80^{\circ} \mathrm{E}\right)$ zonalmean geopotential height and zonal wind responses during early winter for each ensemble member. The three UM7.3 ensemble members with a strong negative NAO-type response (Fig. 9) are identified as runs 1, 5, and 6 in Fig. 10. These three members all show geopotential height increases throughout the atmospheric column poleward of $55^{\circ} \mathrm{N}$ and height decreases between $30^{\circ}$ and $50^{\circ} \mathrm{N}$. Accordingly, the zonal winds are weakened near $55^{\circ} \mathrm{N}$ throughout the atmospheric column, but especially near the tropopause $(300 \mathrm{hPa})$. This is indicative of a weakened midlatitude jet stream and storm track and is characteristic of the negative NAO phase (Hurrell 1995). UM7.3 run 7 shows a similar pattern but shifted poleward such that it does not project very strongly onto the NAO. The one UM7.3 ensemble member with a positive NAO-type response (Fig. 9) is clearly identifiable as run number 8 in Fig. 10. CAM3 run 4 shows a clear negative NAO-type response, whereas runs 3 and 5 show weaker and slightly poleward shifted negative NAO-type responses. The superensemble mean

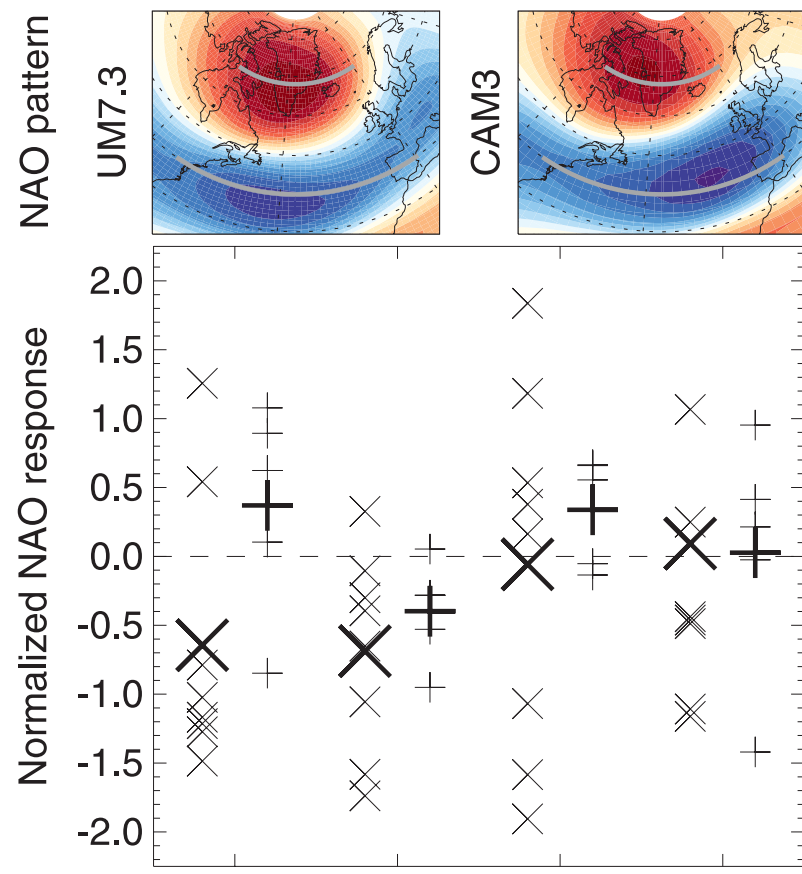

Sep-Oct Nov-Dec Jan-Feb Mar-Apr

FIG. 9. (top) NAO patterns in UM7.3 and CAM3, defined as the leading empirical orthogonal function of September-April $500-\mathrm{hPa}$ geopotential height over the Atlantic sector $\left(0^{\circ}-80^{\circ} \mathrm{W}\right.$, $\left.30^{\circ}-90^{\circ} \mathrm{N}\right)$. The gray lines denote the locations used to define the NAO index. (bottom) The NAO index responses in UM7.3 (crosses) and CAM3 (pluses). The smaller symbols represent the NAO responses in each ensemble member whereas the larger symbols show the ensemble-mean responses. The NAO indices are normalized by their standard deviation.

(combining all UM7.3 and CAM3 runs together) shows a pattern of height increases over the high latitudes (significant at the $90 \%$ level) and height decreases centered around $50^{\circ} \mathrm{N}$ (significant at the $95 \%$ level) with zonal wind decreases centered at $60^{\circ} \mathrm{N}$ and zonal wind increases an $35^{\circ} \mathrm{N}$ (both significant at the $95 \%$ level). Thus, in early winter at least, the simulations are suggestive of a negative NAO-type response to recent Arctic sea ice loss. If this is a robust response, however, it appears quite weak and easily exceeded by intrinsic atmospheric variability. One implication of this result is that such a circulation response to Arctic sea ice loss may be difficult, or impossible, to detect in observations as it could easily be masked by internal variability.

The early winter circulation response found here is rather different to that shown by Strey et al. (2010) for October-November and Orsolini et al. (2012) for December. The response in Strey et al. (2010) was characterized by low SLP over the Arctic Ocean, northern Pacific, and eastern North America and high sea level pressure (SLP) over the North Atlantic and western North 

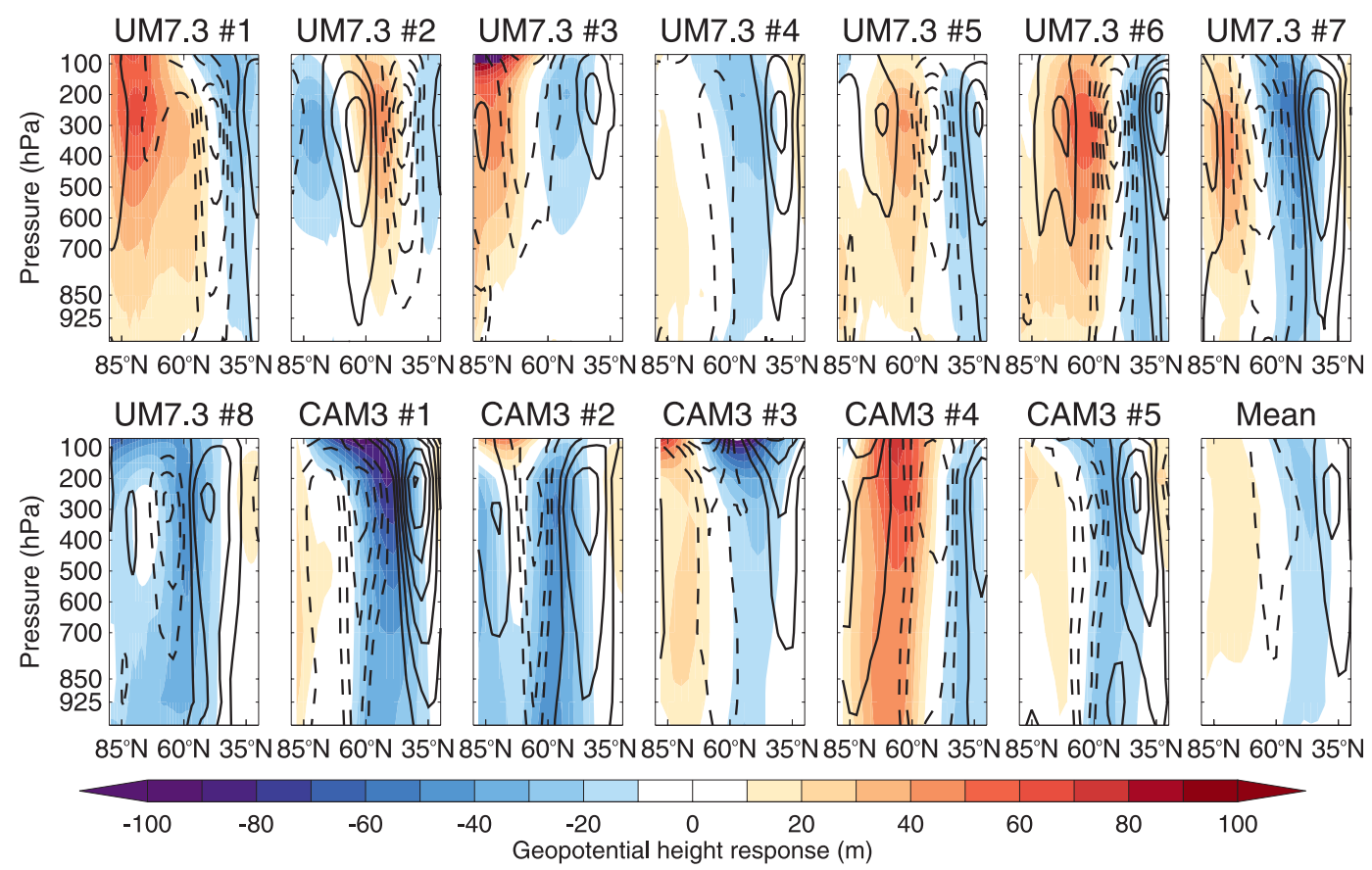

FIG. 10. Atlantic sector $\left(0^{\circ}-80^{\circ} \mathrm{W}\right)$ zonal-mean geopotential height responses (shading) and zonal wind responses (contours) during November-December. Each plot corresponds to the response in an individual ensemble member with the exception of the bottom-right plot, which shows the superensemble mean response. Contours are drawn at intervals of $1 \mathrm{~m} \mathrm{~s}^{-1}$ with solid contours denoting a positive response and dashed contours denoting a negative response. The zero contour is not plotted.

America with little resemblance to either phase of the NAO (their Fig. 6). Orsolini et al. (2012) identified low SLP over the North Pacific and far North Atlantic and high SLP over the eastern midlatitude Atlantic, Canada, and Siberia (their Fig. 3). Their pattern of response over the Atlantic sector was analogous to a positive NAO-type response. Recall that both of these studies were focused on the atmospheric response to dramatic sea ice loss in one year (2007) whereas we are concerned with longer-term changes. Further, the Orsolini et al. (2012) simulations included changes in SST as well as sea ice. Both of these factors may help explain the discrepancies seen. Equally, they could also arise from model sensitivities or contamination of the forced response to sea ice loss by intrinsic atmospheric variability.

Other studies focusing on the atmospheric response to projected future Arctic sea ice loss have also found contrasting winter circulation responses [for a recent review, see Bader et al. (2011)]. Magnusdottir et al. (2004) found a consistent negative NAO-type response in December through March. This result was generally supported by the later study of Seierstad and Bader (2009). In contrast, Singarayer et al. (2006) found an average winter (December-February) response that had little resemblance to the NAO. Deser et al. (2010) found a strong negative NAO-type response in February, but an early winter response that was not NAO-like. Again, these discrepancies may result from the different forcings applied in each study, the range of models employed, or insufficient ensemble size to completely average out the large influence of intrinsic variability. In this study, we have attempted to reduce the effects of these impediments by using two independent models with identical forcings and by running multiple realizations. However, in both models the circulation responses differ considerably among their ensemble members. While further work is needed to fully understand the reasons for the disparity amongst different studies, this study has emphasized that one of the foremost limitations to understanding the circulation response is the large intrinsic variability of the highlatitude circulation.

\section{e. Stratospheric response}

Figure 11 shows the 70-hPa (lower stratospheric) air temperature and zonal wind responses, which are of largest magnitude during mid and late winter. The models show opposite responses in midwinter: UM7.3 shows a stratospheric warming response and decreased zonal winds, indicative of a weakened stratospheric polar vortex, whereas CAM3 shows a general cooling response with strengthened winds (mainly over the 


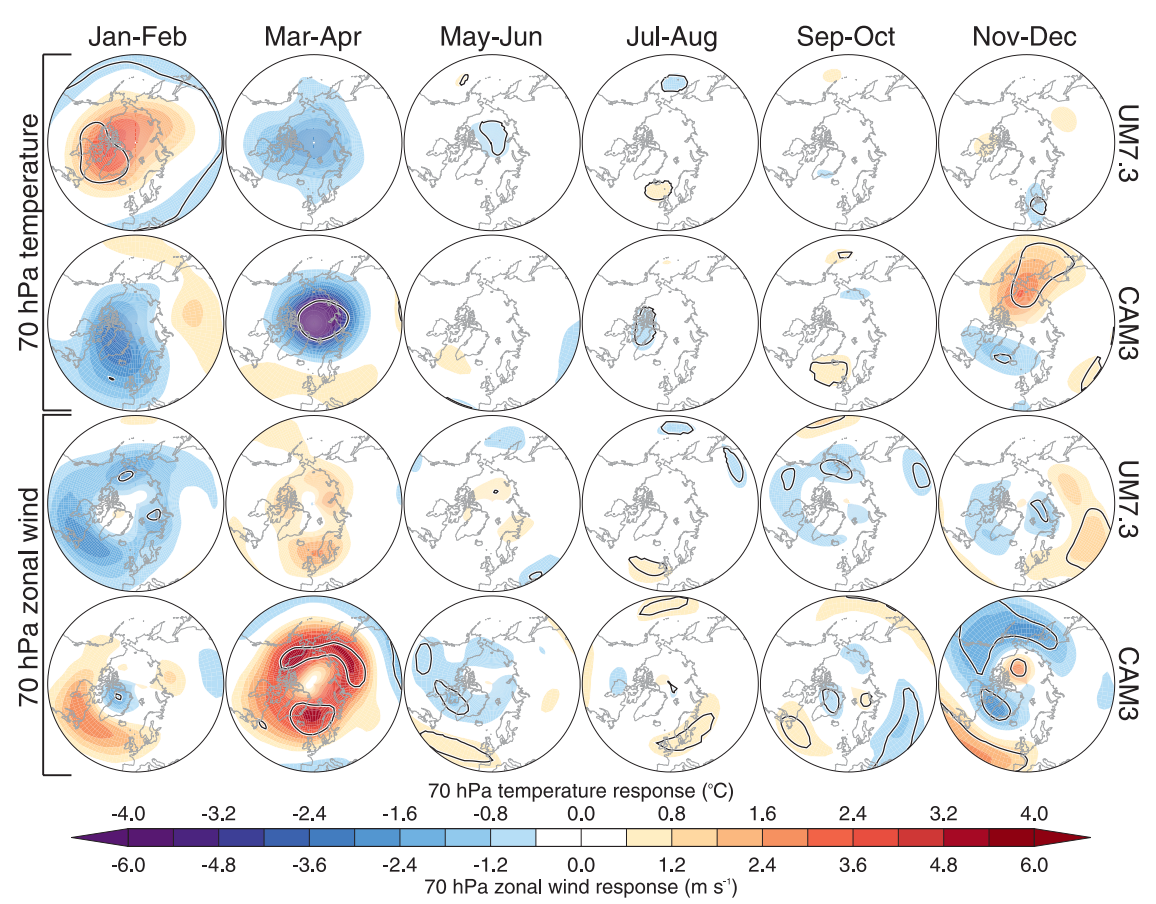

FIG. 11. Ensemble-mean 70-hPa (top two rows) air temperature responses and (bottom two rows) zonal wind responses in the two models. Black lines denote ensemble-mean linear responses that are statistically significant at the $95 \%$ level.

Atlantic). Although there are areas that show a statistically significant stratospheric response in midwinter (and early winter), these should be interpreted with caution as these responses vary considerably between ensemble members (not shown). There is closer agreement between the models and between ensemble members for the late winter responses. Both models depict stratospheric cooling over the polar cap and increased zonal winds centered near $65^{\circ} \mathrm{N}$-both characteristic of a strengthened stratospheric polar vortex (Fig. 11). This response is stronger in the CAM3 ensemble mean than in the UM7.3 ensemble mean and only statistically significant in the former. An ensemble-mean 70-hPa cooling response is identifiable during February to April (but strongest in March) in CAM3 but only during April in UM7.3 (not shown).

Figure 12 shows the zonal-mean zonal wind and temperature responses during late winter in each of the ensemble members. All five CAM 3 ensemble members display strengthened westerly winds centered near $65^{\circ} \mathrm{N}$ and cooling in the polar stratosphere. The wind response is confined to the stratosphere in four members but extends to the lower troposphere in one member. The robustness of the stratospheric response between the CAM3 ensemble members is striking given the large variability in the polar stratosphere and the inconsistencies between the midwinter responses in the different ensemble members. Turning to UM7.3, five of the eight ensemble members show a strengthening of the lower stratospheric zonal winds near $65^{\circ} \mathrm{N}$, with considerable range in magnitude. However, the other three ensemble members exhibit a roughly opposite response and suggest a weakening of the stratospheric polar vortex. This highlights the strong influence of intrinsic variability in the stratosphere in UM7.3. As a superensemble, 10 of 13 ensemble members display some expression of stratospheric cooling and strengthened zonal winds during late winter in response to Arctic sea ice loss. The superensemble mean shows a statistically significant (at the $95 \%$ level) $2^{\circ} \mathrm{C}$ cooling response over the polar cap and a marginally significant $(85 \%$ level) $1-2 \mathrm{~m} \mathrm{~s}^{-1}$ increase in the stratospheric zonal winds at $65^{\circ} \mathrm{N}$.

The lower stratospheric responses are suggestive (at least in CAM3) of a causal link between Arctic sea ice loss and a stronger late winter polar vortex. To our knowledge, the only previous study that has attempted to model the stratospheric response to Arctic sea ice loss is that of Scinocca et al. (2009). Although their focus was on polar ozone concentrations in response to a hypothetical complete removal of summer Arctic sea ice, Scinocca et al. also found the primary stratospheric response to occur in March. In their model simulations, sea 

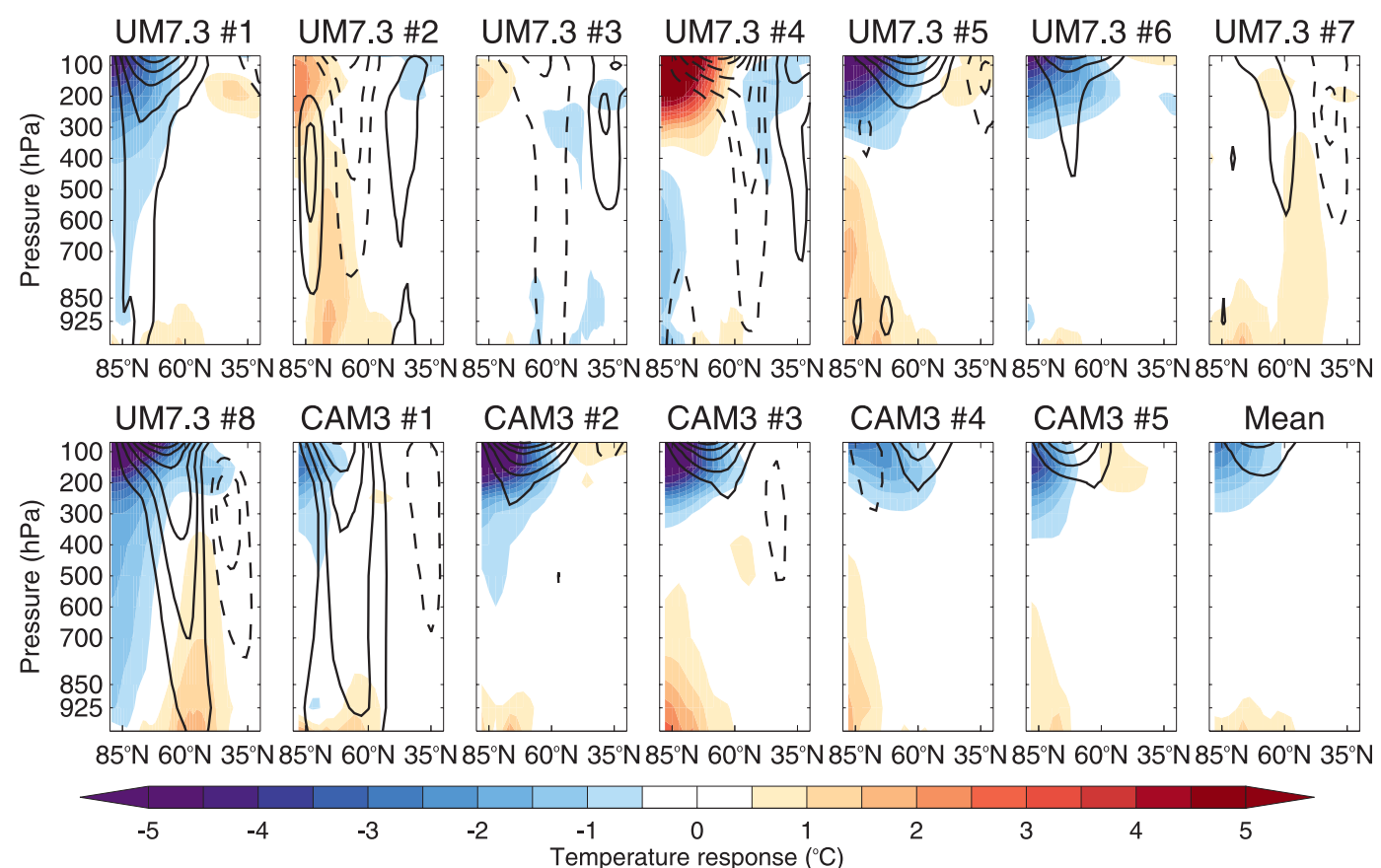

FIG. 12. Zonal-mean air temperature responses (shading) and zonal wind responses (contours) during MarchApril. Each plot corresponds to the response in an individual ensemble member with the exception of the bottomright plot, which shows the superensemble mean response. Contours are drawn at intervals of $1 \mathrm{~m} \mathrm{~s}^{-1}$ with solid contours denoting a positive response and dashed contours denoting a negative response. The zero contour is not plotted.

ice loss induced cooling of the Arctic stratosphere, which they attributed to primarily dynamical effects and in particular, weaker high-latitude descent. This consistency in the responses between the two studies is in spite of the fact that Scinocca et al. (2009) used a "high top" model with better vertical resolution in the stratosphere and more sophisticated stratospheric chemistry than either of the models used here.

\section{Discussion and conclusions}

Our aim in this investigation was to understand better the atmospheric changes that may have occurred in response to observed Arctic sea ice reductions over the past three decades. We have presented results from simulations using two independent AGCMs in which the only prescribed forcing was variations in observed Arctic sea ice concentrations (and directly associated SST changes) between 1979 and 2009.

The results suggest that the atmospheric impacts of Arctic sea ice loss have been manifested most strongly within the maritime and coastal Arctic. The most robust elements of the atmospheric response are found to occur in close proximity to regions of sea ice loss and in the lowermost atmosphere, and are very closely related to changes in the surface energy budget. The model evidence presented strongly suggests that recent sea ice loss has driven increased energy transfer from the ocean to the atmosphere (Figs. 2 and 3), enhanced warming and moistening of the lower troposphere (Figs. 5 and 6), decreased the strength of the surface inversion (Fig. 5), and increased lower tropospheric thickness (Fig. 8), all of which have been manifested most strongly in autumn and early winter. Similar responses have been found in other modeling studies (Kumar et al. 2010; Strey et al. 2010; Orsolini et al. 2012; Porter et al. 2012) and observational evidence suggests these changes are already detectable in reality (Serreze et al. 2009; Overland and Wang 2010; Screen and Simmonds 2010a,b; Serreze and Barry 2011; Kurtz et al. 2011). Interestingly, there is little evidence of an ice-driven temperature response above the stable boundary layer (except for in CAM3 during early winter), although observations and reanalyses suggest that warming aloft has occurred (Graversen et al. 2008; Screen and Simmonds 2010a, 2011; Screen et al. 2012). Screen et al. (2012) show that the observed Arctic warming aloft, unlike that near the surface, is likely remotely driven by SST changes outside the Arctic and consequent increases in poleward heat transport into the Arctic.

The results are suggestive of a causal link between Arctic sea ice loss and the negative phase of the NAO 
during early winter (Figs. 8-10). This supports similar linkages found in other modeling studies concerned with the impacts of projected future sea ice loss (e.g., Magnusdottir et al. 2004; Seierstad and Bader 2009; Deser et al. 2010); however, there is considerable disagreement between studies in terms of the timing (early, mid, or late winter) and strength of the response. Our simulations add credence to the statistical associations between sea ice and the NAO revealed by other studies (Francis et al. 2009; Overland and Wang 2010; Wu and Zhang 2010; Strong et al. 2010). We note, however, that despite a moderately robust negative NOA-type response in early winter, we do not find evidence of a typical negative NAO-like response in early winter surface temperature or precipitation (Figs. 5 and 7). Further, the NAO response appears quite weak and easily exceeded by intrinsic atmospheric variability. The latter result is consistent with the view that changes in the NAO are largely brought about by intrinsic atmospheric variability rather than oceanic forcing (Deser and Phillips 2009).

We find some evidence of a late winter lower stratospheric cooling response to Arctic sea ice loss (Figs. 11 and 12). This may have impacts for polar stratospheric ozone concentrations and ultraviolet radiation reaching the surface (Scinocca et al. 2009; Sinnhuber et al. 2011). Whether the record minimum in Arctic stratospheric ozone in March 2011 (Manney et al. 2011) was causally linked to Arctic sea ice changes remains to be addressed.

The attribution and quantification of other aspects of the potential atmospheric response to sea ice loss are hampered by three critical factors. First, we have shown that there are aspects of the response that appear highly sensitive to the model chosen. These include the cloud cover and precipitation responses (Fig. 7). In this regard, is it interesting to note that Kay et al. (2012) find that disparities in cloud changes between different AGCMs explain a large proportion of their varying Arctic climate responses to increasing greenhouse gases. This highlights the importance of multimodel studies. Second, the identification of other potential aspects of the response is limited by large atmospheric intrinsic variability. For example, the midtropospheric circulation and stratospheric responses are generally statistically insignificant in the ensemble mean (Figs. 8 and 11) and differ widely among ensemble members. While larger ensembles may have led to more robust responses, if very large ensembles are required to detect such responses, it implies that they are small in comparison to internal variability. Here we are primarily interested in the elements of the response that may be observable in nature. Third, because of the prescription of SSTs, the full effect of sea ice changes on climate cannot be assessed from our simulations because of the lack of oceanic feedback. However, our experiments do enable the isolation of sea-ice-induced atmospheric changes, which can be difficult to disentangle in coupled model experiments and in nature.

During the winters 2009/10 and 2010/11 North America, Europe, and East Asia experienced anomalously cold conditions along with record snowfalls. Cohen et al. (2012a,b) suggest that these events are part of a longer-term trend toward colder boreal winters. Several studies have recently speculated that an increased occurrence of cold winters and snowfall in the midlatitudes may be driven, in part, by Arctic sea ice loss (Honda et al. 2009; Petoukhov and Semenov 2010; Overland: et al. 2011; Lui et al. 2012; Liu et al. 2012; Francis and Vavrus 2012) and/or reductions in snow cover (Cohen et al. 2012a). With these possible connections in mind, we examined the land surface temperature and snowfall responses over Europe, North America, and East Asia in our model experiments (not shown). We note, however, that our simulations do not include the winters of 2010 or 2011 (they end in December 2009). We found a localized surface cooling response over northeast Europe in early winter in UM7.3 (but not CAM3), consistent with the 925-hPa temperature response shown earlier in Fig. 5. However, we found no robust (between models) or widespread cooling, or increased snowfall, in our simulations in response to the rapid Arctic sea ice loss over the last three decades. While this does not rule out that low sea ice conditions played a driving role in the cold winters of 2009/10 and 2010/11, it does, however, suggest that proposed links between multidecadal sea ice changes and boreal winter cooling may be premature.

We close by commenting that the atmospheric response identified here is weaker and less spatially extensive and identifiable in fewer atmospheric variables than that found in CAM3 in response to projected sea ice loss by Deser et al. (2010). In large part this likely reflects that our sea ice forcing is smaller than that used by Deser et al. Arctic sea ice loss over the past three decades, although unprecedented, has been small in comparison to that which is anticipated by the end of this century. It is perhaps unsurprising then that the Deser et al. (2010) model simulations comparing late twentyfirst-century to late twentieth-century sea ice conditions yield a stronger and more coherent atmospheric response than found here. Thus, while the atmospheric impacts of observed sea ice change appear to have been mostly manifest locally and primarily in autumn and early winter, more spatially and temporally widespread responses are possible in the future if Arctic sea ice loss continues. 
Acknowledgments. The idea for a cross-model study arose during a visit by J. Screen to NCAR in May 2011. J. Screen thanks M. Holland for hosting this visit and NCAR for financial support. F. Drost, J. Arblaster, and M. Rezny are thanked for their help setting up the UM7.3 simulations, which were supported by an award under the Merit Allocation Scheme on the NCI National Facility at the ANU. J. Screen and I. Simmonds are supported by funding by the Australian Research Council. C. Deser and R. Tomas gratefully acknowledge support from the NSF Office of Polar Programs. Three anonymous reviewers are thanked for their time and expert comments.

\section{REFERENCES}

Alexander, M., U. Bhatt, J. Walsh, M. Timlin, J. Miller, and J. Scott, 2004: The atmospheric response to realistic Arctic sea ice anomalies in an AGCM during winter. J. Climate, 17, 890905.

Bader, J., M. Mesquita, K. Hodges, N. Keenlyside, S. Osterhus, and M. Miles, 2011: A review on Northern Hemisphere sea-ice, storminess and the North Atlantic Oscillation: Observations and projected changes. Atmos. Res., 101, 809-834.

Bhatt, U., M. Alexander, C. Deser, J. Walsh, J. Miller, M. Timlin, J. Scott, and R. Tomas, 2008: The atmospheric response to realistic reduced summer Arctic sea ice anomalies. Arctic Sea Ice Decline: Observations, Projections, Mechanisms, and Implications, Geophys. Monogr., Vol. 180, Amer. Geophys. Union, 91-110.

Bintanja, R., R. Graversen, and W. Hazeleger, 2011: Arctic winter warming amplified by the thermal inversion and consequent low infrared cooling to space. Nat. Geosci., 4, 758-761.

Blüthgen, J., R. Gerdes, and M. Werner, 2012: Atmospheric response to the extreme arctic sea ice conditions in 2007. Geophys. Res. Lett., 39, L02707, doi:10.1029/2011GL050486.

Boé, J., A. Hall, and X. Qu, 2009: September sea ice cover in the Arctic Ocean projected to vanish by 2100 . Nat. Geosci., 2,341343.

Budikova, D., 2009: Role of Arctic sea ice in global atmospheric circulation: A review. Global Planet. Change, 68, 149-163.

Chung, C., and P. Räisänen, 2011: Origin of the Arctic warming in climate models. Geophys. Res. Lett., 38, L21704, doi:10.1029/ 2011GL049816.

Cohen, J., J. Furtado, M. Barlow, V. Alexeev, and J. Cherry, 2012a: Arctic warming, increasing snow cover and widespread boreal winter cooling. Environ. Res. Lett., 7, 014007, doi:10.1088/ 1748-9326/7/1/014007.

$-, \ldots,-$, and $\_, 2012 \mathrm{~b}$ : Asymmetric seasonal temperature trends. Geophys. Res. Lett., 39, L04705, doi:10.1029/2011GL050582.

Collins, W., and Coauthors, 2006: The formulation and atmospheric simulation of the Community Atmosphere Mode version 3 (CAM3). J. Climate, 19, 2144-2161.

Comiso, J., 2012: Large decadal decline of the Arctic multiyear ice cover. J. Climate, 25, 1176-1193.

_ C. Parkinson, R. Gersten, and L. Stock, 2008: Accelerated decline in Arctic sea ice cover. Geophys. Res. Lett., 35, L01703, doi:10.1029/2007GL031972.

Deser, C., and A. Phillips, 2009: Atmospheric circulation trends, 1950-2000: The relative roles of sea surface temperature forcing and direct atmospheric radiative forcing. J. Climate, 22, 396-413.

G. Magnusdottir, R. Saravanan, and A. Phillips, 2004: The effects of North Atlantic SST and sea ice anomalies on the winter circulation in CCM3. Part II: Direct and indirect components of the response. J. Climate, 17, 877-889.

- R. Tomas, M. Alexander, and D. Lawrence, 2010: The seasonal atmospheric response to projected Arctic sea ice loss in the late twenty-first century. J. Climate, 23, 333-351.

Francis, J., and S. Vavrus, 2012: Evidence linking Arctic amplification to extreme weather in mid-latitudes. Geophys. Res. Lett., 39, L06801, doi:10.1029/2012GL051000.

, W. Chen, D. Leathers, J. Miller, and D. Veron, 2009: Winter Northern Hemisphere weather patterns remember summer Arctic sea ice extent. Geophys. Res. Lett., 36, L07503, doi:10.1029/2009GL037274.

Ghatak, D., A. Frei, G. Gong, J. Stroeve, and D. Robinson, 2010: On the emergence of an Arctic amplification signal in terrestrial Arctic snow extent. J. Geophys. Res., 115, D24105, doi:10.1029/2010JD014007.

Graversen, R., T. Mauritsen, M. Tjernström, E. Källén, and G. Svensson, 2008: Vertical structure of recent Arctic warming. Nature, 451, 53-56.

Honda, M., J. Inoue, and S. Yamane, 2009: Influence of low Arctic sea-ice minima on anomalously cold Eurasian winters. Geophys. Res. Lett., 36, L08707, doi:10.1029/2008GL037079.

Hurrell, J., 1995: Decadal trends in the North Atlantic Oscillation: Regional temperatures and precipitation. Science, 269, 676-679.

, J. Hack, D. Shea, J. Caron, and J. Rosinski, 2008: A new sea surface temperature and sea ice boundary dataset for the Community Atmosphere Model. J. Climate, 21, 5145-5153.

Jaiser, R., K. Dethloff, D. Handorf, A. Rinke, and J. Cohen, 2012: Impact of sea ice cover changes on the Northern Hemisphere atmospheric winter circulation. Tellus, 64, 11595, doi:10.3402/ tellusa.v64i0.11595.

Kay, J., and A. Gettelman, 2009: Cloud influence on and response to seasonal Arctic sea ice loss. J. Geophys. Res., 114, D18204, doi:10.1029/2009JD011773.

, M. Holland, C. Bitz, E. Blanchard-Wrigglesworth, A. Gettelman, A. Conley, and D. Bailey, 2012: The influence of local feedbacks and northward heat transport on the equilibrium Arctic climate response to increased greenhouse gas forcing. J. Climate, 25, 5433-5450.

Kumar, A., and Coauthors, 2010: Contribution of sea ice loss to Arctic amplification. Geophys. Res. Lett., 37, L21701, doi:10.1029/ 2010GL045022.

Kurtz, N., T. Markus, S. Farrell, D. Worthern, and L. Boisvert, 2011: Observations of recent Arctic sea ice volume loss and its impact on ocean-atmosphere energy exchange and ice production. J. Geophys. Res., 116, C04015, doi:10.1029/2010JC006235.

Kwok, R., and D. Rothrock, 2009: Decline in Arctic sea ice thickness from submarine and ICEsat records: 1958-2008. Geophys. Res. Lett., 36, L15501, doi:10.1029/2009GL039035.

Liu, J., J. Curry, H. Wang, M. Song, and R. Horton, 2012: Impact of declining Arctic sea ice on winter snowfall. Proc. Natl. Acad. Sci. USA, 109, 4074-4079; Corrigendum, 109, 6781-6783.

Lui, N., J. Lui, Z. Zhang, H. Chen, and M. Song, 2012: Is extreme Arctic sea ice anomaly in 2007 a key contributor to severe January 2008 snowstorm in China? Int. J. Climatol., 32, 20812087.

Magnusdottir, G., C. Deser, and R. Saravanan, 2004: The effects of North Atlantic SST and sea ice anomalies on the winter 
circulation in CCM3. Part I: Main features and storm track characteristics of the response. J. Climate, 17, 857-876.

Manney, G., and Coauthors, 2011: Unprecedented Arctic ozone loss in 2011. Nature, 478, 469-475.

Martin, G. M., and Coauthors, 2011: The HadGEM2 family of Met Office Unified Model climate configurations. Geosci. Model Dev., 4, 723-757.

Maslanik, J., J. Stroeve, C. Fowler, and W. Emery, 2011: Distribution and trends in Arctic sea ice age through spring 2011. Geophys. Res. Lett., 38, L13502, doi:10.1029/2011GL047735.

Orsolini, Y., R. Senan, R. Benestad, and A. Melsom, 2012: Autumn atmospheric response to the 2007 low Arctic sea ice extent in coupled ocean-atmosphere hindcasts. Climate Dyn., 38, $2437-$ 2448.

Overland, J., and M. Wang, 2010: Large-scale atmospheric circulation changes are associated with the recent loss of Arctic sea ice. Tellus, 62A, 1-9.

_- K. Wood, and M. Wang, 2011: Warm Arctic-cold continents: Climate impacts of the newly open Arctic sea. Polar Res., 30, 15787, doi:10.3402/polar.v30i0.15787.

Palm, S., S. Strey, J. Spinhirne, and T. Markus, 2010: Influence of Arctic sea ice extent on polar cloud fraction and vertical structure and implications for regional climate. J. Geophys. Res., 115, D21209, doi:10.1029/2010JD013900.

Perovich, D., J. Richter-Menge, K. Jones, and B. Light, 2008: Sunlight, water and ice: Extreme Arctic sea ice melt during the summer of 2007. Geophys. Res. Lett., 35, L11501, doi:10.1029/ 2008GL034007.

Petoukhov, V., and V. Semenov, 2010: A link between reduced BarentKara sea ice and cold winter extremes over northern continents. J. Geophys. Res., 115, D21111, doi:10.1029/2009JD013568.

Polyak, L., and Coauthors, 2010: History of sea ice in the Arctic. Quat. Sci. Rev., 29, 1757-1778.

Porter, D., J. Cassano, and M. Serreze, 2012: Local and large-scale atmospheric responses to reduced Arctic sea ice and ocean warming in the WRF model. J. Geophys. Res., 117, D11115, doi:10.1029/2011JD016969.

Schweiger, A., R. Lindsay, S. Vavrus, and J. Francis, 2008: Relationships between Arctic sea ice and clouds during autumn. J. Climate, 21, 4799-4810; Corrigendum, 22, 2793.

—_ - J. Zhang, M. Steele, H. Stern, and R. Kwok, 2011: Uncertainty in modeled Arctic sea ice volume. J. Geophys. Res., 116, C00D06, doi:10.1029/2011JC007084.

Scinocca, J., M. Reader, D. Plummer, M. Sigmond, P. Kushner, T. Shepherd, and A. Ravishankara, 2009: Impact of sudden Arctic sea-ice loss on stratospheric polar ozone. Geophys. Res. Lett., 36, L24701, doi:10.1029/2009GL041239.

Screen, J., and I. Simmonds, 2010a: The central role of diminishing sea ice in recent Arctic temperature amplification. Nature, 464, 1334-1337.

$\ldots$, and - 2010b: Increasing fall-winter energy loss from the Arctic Ocean and its role in Arctic temperature amplification. Geophys. Res. Lett., 37, L16707, doi:10.1029/2010GL044136.

— ERA-40 reanalysis: A closer look. J. Climate, 24, 2620-2627. , and - 2012: Declining summer snowfall in the Arctic: Causes, impacts and feedbacks. Climate Dyn., 38, 2243-2256.
_ C. Deser, and I. Simmonds, 2012: Local and remote controls on observed Arctic warming. Geophys. Res. Lett., 39, L10709, doi:10.1029/2012GL051598.

Seierstad, I., and J. Bader, 2009: Impact of a projected future Arctic sea ice reduction on extratropical storminess and the NAO. Climate Dyn., 33, 937-943.

Serreze, M., and R. Barry, 2011: Processes and impacts of Arctic amplification: A research synthesis. Global Planet. Change, 77, 85-96.

— M. Molland, and J. Stroeve, 2007: Perspectives on the Arctic's shrinking sea-ice cover. Science, 315, 1533-1536.

_ - A. Barrett, J. Stroeve, D. Kindig, and M. Holland, 2009: The emergence of surface-based Arctic amplification. Cryosphere, 3, 11-19.

Simmonds, I., and K. Keay, 2009: Extraordinary September Arctic sea ice reductions and their relationships with storm behavior over 1979-2008. Geophys. Res. Lett., 36, L19715, doi:10.1029/ 2009GL039810.

Singarayer, J., J. Bamber, and P. Valdes, 2006: Twenty-first-century climate impacts from a declining Arctic sea ice cover. J. Climate, 19, 1109-1125.

Sinnhuber, B.-M., G. Stiller, R. Ruhnke, T. von Clarmann, S. Kellmann, and J. Aschmann, 2011: Arctic winter 2010/2011 at the brink of an ozone hole. Geophys. Res. Lett., 38, L24814, doi:10.1029/2011GL049784.

Solomon, S., D. Qin, M. Manning, Z. Chen, M. Marquis, K. Averyt, M. Tignot, and H. Miller, Eds., 2007: Climate Change 2007: The Physical Science Basis. Cambridge University Press, $996 \mathrm{pp}$.

Strey, S., W. Chapman, and J. Walsh, 2010: The 2007 sea ice minimum: Impacts on the Northern Hemisphere atmosphere in late autumn and early winter. J. Geophys. Res., 115, D23103, doi:10.1029/2009JD013294

Stroeve, J., M. Holland, W. Meier, T. Scambos, and M. Serreze, 2007: Arctic sea ice decline: Faster than forecast. Geophys. Res. Lett., 34, L09501, doi:10.1029/2007GL029703.

_ , M. Serreze, M. Holland, J. Kay, J. Maslanik, and A. Barrett, 2011: The Arctic's rapidly shrinking sea ice cover: A research synthesis. Climatic Change, 110, 1005-1027.

Strong, C., G. Magnusdottir, and H. Stern, 2010: Observed feedback between winter sea ice and the North Atlantic Oscillation. J. Climate, 22, 6021-6032.

Symon, C., L. Arris, and B. Heal, Eds., 2005: Arctic Climate Impact Assessment. Cambridge University Press, $1042 \mathrm{pp}$.

Vavrus, S., and D. Waliser, 2008: An improved parameterization for simulating Arctic cloud amount in the CCSM3 climate model. J. Climate, 21, 5673-5687.

Wang, M., and J. Overland, 2009: A sea ice free summer Arctic within 30 years? Geophys. Res. Lett., 36, L07502, doi:10.1029/ 2009GL037820.

Wu, Q., and X. Zhang, 2010: Observed forcing-feedback processes between Northern Hemisphere atmospheric circulation and Arctic sea ice coverage. J. Geophys. Res., 115, D14199, doi:10.1029/2009JD013574.

Yang, X.-Y., J. Fyfe, and G. Flato, 2010: The role of poleward energy transport in Arctic temperature evolution. Geophys. Res. Lett., 37, L14803, doi:10.1029/2010GL043934. 